\title{
Contract employment policy and research productivity of knowledge workers: An analysis of Spanish universities
}

\author{
Esteban Lafuente ${ }^{1}$ \\ Department of Management, Universitat Politècnica de Catalunya (Barcelona Tech) \\ EPSEB, Av. Gregorio Marañón, 44-50, 3era planta. 08028. Barcelona. Spain \\ Email: esteban.lafuente@upc.edu \\ Jasmina Berbegal-Mirabent \\ Department of Economy and Business Organization, Universitat Internacional de \\ Catalunya \\ C. Immaculada, 22. 08017. Barcelona, Spain \\ Email: jberbegal@uic.es
}

Please cite as: Lafuente, E., Berbegal-Mirabent, J. (2017). Contract employment policy and research productivity of knowledge workers: An analysis of Spanish universities. International Journal of Human Resource Management, in press. DOI:

$10.1080 / 09585192.2017 .1323226$

Acknowledgements: For their ideas and insightful comments that helped us to improve the paper we are grateful to Rodrigo Rabetino (University of Vaasa, Finland), László Szerb (University of Pécs, Hungary), Yancy Vaillant (Toulouse Business School, France) and Ferran Vendrell-Herrero (University of Birmingham, UK). Esteban Lafuente acknowledges financial support by the Spanish Ministry of Science and Innovation (Grant number: ECO2013-48496-C4-4-R).

\footnotetext{
${ }^{1}$ Corresponding author
} 
Contract employment policy and research productivity of knowledge workers: An analysis of Spanish universities

\begin{abstract}
:
This article investigates how contract employment practices adopted by universitiesfixed-term contracts and permanent contracts - impact research productivity measured in terms of publications in scholarly journals. The empirical application considers the Spanish public higher education system for the period 2002-2008. We report an inverse U-shaped relationship between the rate fixed-term contracts and the research productivity of Spanish universities. That is, contract policies based on fixed-term contracts are conducive to research productivity; however, beyond a critical threshold value increases in the proportion of fixed-term contracts are associated with declining research productivity. These findings reveal that contract employment policies shape research productivity, and that flexible and balanced contract practices are critical for enhancing universities' research productivity. The results suggest that the excessive use of fixed-term contracts might create an unstable working environment that limits the universities' capacity to capitalize on their knowledge workers. Policy implications and future research avenues are discussed.
\end{abstract}

Keywords: Contract employment, knowledge workers, research scientists, universities, research productivity

JEL classification: I23, J45 


\section{Contract employment policy and research productivity of knowledge workers: An analysis of Spanish universities}

\section{Introduction}

Governments have traditionally devoted considerable resources to finance $R \& D$ and scientific outcomes, either through tax policy or direct investment. The recent trend on the creation of a knowledge-based economy has resulted in reforms and investments in $\mathrm{R} \& \mathrm{D}$ infrastructures, including universities and research centers (European Commission, 2007). Additionally, the growing awareness of the importance of universities as key pillars for the consolidation of knowledge-based economies has led European governing bodies to adopt specific policies within the EU 2020 strategic plan aimed at stimulating knowledge creation and diffusion, as well as scientific productivity among universities (European Commission, 2015).

Nevertheless, universities do not realize the generally positive effects of R\&D investments at the same intensity (European Commission, 2013). Research productivity - in terms of publication metrics - is not only heterogeneous between universities, but also in terms of the factors explaining productivity differences over time. A common presumption is that both the institutional setting governing public universities (King, 2004) and scientists' career incentives (Reich, 2013) play a decisive role in shaping universities' scientific productivity.

Notwithstanding the increased relevance of research productivity for policy makers and universities, the majority of studies analyze academics' productivity in US universities whose institutional characteristics - e.g., autonomy, job mobility and stratification - are not representative of most European settings (see, e.g., Agarwal \& Ohyama, 2014; Goldfarb, 2008; Lee \& Bozeman, 2005). US universities enjoy full autonomy to recruit and promote scientists, who can both bargain their working conditions and search for better positions in other universities via the job market (Clark, 1993). Also, the US system is stratified and universities can adapt scientists' workloads according to the orientation of the institution (research versus teaching) (Ehrenberg, Kasper, \& Rees, 1991). 
The picture in Europe is quite different. ${ }^{2}$ While the UK university system shares most characteristics of the US system aforementioned, other contexts-e.g., France, Finland, Germany, Hungary, Italy or Spain — have a centralized system in which public universities cannot differentiate openly their orientation, and in which job calls are conditioned by governmental policy (Lissoni, Mairesse, Montobbio, \& Pezzoni, 2011; Lutter \& Schröder, 2016). Also, scientists' working conditions are defined by national laws, and regulatory procedures govern recruitment and promotion processes.

The characteristics of centralized systems arguably limit competition between universities for recruiting or promoting productive scientists, and reforms adopted in various EU countries seek to correct these flaws and improve research productivity. Thus, a critical question is, do universities' contract employment policies affect research productivity? In Europe, studies on research productivity mostly examine the effects of demographic variables and industry collaborations (Balsmeier \& Pellens, 2014; Breschi, Lissoni, \& Montobbio, 2008; Lutter \& Schröder, 2016), as well as the life cycle of research productivity (Bonaccorsi \& Daraio, 2003; Hall, Mairesse, \& Turner, 2007). The analysis of the effect of universities' contract employment policies on research productivity has been largely sidelined in previous research.

Recently, a stream of research has emphasized that research scientists are archetypal knowledge workers whose productivity level is affected by employment conditions, influence on work arrangements and the capacity to manage career development (Harney, Monks, Alexopoulos, Buckley, \& Hogan, 2014; Lissoni et al., 2011; Swart, 2007). The analysis of the relationship between employment practices and research productivity is the focus of this study. Specifically, this paper evaluates the impact of universities' contract employment practices-i.e., fixed-term contracts and permanent contracts - on research productivity, measured via publication metrics.

Fixed-term contracts and mobility are often invoked as a solution to the potential problems resulting from academic inbreeding, including lower creativity and productivity levels among scientists, and the development of narrower scientist networks (see, e.g., Horta, Veloso, \& Grediaga, 2010; Song, Almeida, \& Wu, 2003). However, employment practices heavily reliant on fixed-term contracts may be

\footnotetext{
${ }^{2}$ Additional qualitative information on the characteristics of public universities' evaluation systems was obtained through an informal round of contacts with scholars from various European countries. For their valuable comments, we are indebted to Rodrigo Rabetino (University of Vaasa, Finland), László Szerb (University of Pécs, Hungary), Yancy Vaillant (Toulouse Business School, France) and Ferran VendrellHerrero (University of Birmingham, UK).
} 
detrimental to long-term career development, and increase job insecurity by preventing researchers from accessing employment opportunities and working conditions that are core to their careers (Fuller \& Unwin, 2010; Harney et al., 2014).

The empirical application considers the Spanish public university system between 2002 and 2008. This setting is attractive because, similar to other European countries, Spain underwent major reforms in the university's regulatory framework seeking to make a better use of publicly funded R\&D. Reforms brought about important challenges for universities in that they are now called to prioritize knowledge-oriented outputs, which led to drastic modifications in their strategic model and human resource management policies. Therefore, the Spanish setting offers the opportunity to analyze how universities match their new objectives to their contract employment practices in a context where scientists have strong publication incentives, and where their publishing incentives are potentially decoupled with the characteristics of their contracts.

This article contributes to the literature in two main ways. First, this study looks into the role of contract employment practices on research productivity, answering the call made by Currie, Tempest, and Starkey (2006), Swart (2007) and Donnelly (2009) for more research on scientists' productivity in contexts where contract practices might create uncertain conditions for researchers. Our results pointing to an inverse U-shaped effect of fixed-term contracts on research productivity suggest that universities promote HR structures that not always match the characteristics of the knowledge of scientists. In this sense, this study extends the work by Lepak and Snell (2002) by showing how knowledge workers - i.e., scientists - respond to different human resource practices in knowledge-based organizations, in our case universities.

Second, the proposed analysis generates valuable insights with practical application. The analysis of the effects of contract employment on scientists' productivity has increasingly drawn policy makers' attention as a result of their interest in enhancing the effectiveness of the public funding of science. By examining the productivity outcomes that flow from different employment practices universities might be in a better position to understand how to capitalize on the knowledge of scientists.

\section{Background literature}

\subsection{Human resource architecture}

Literature rooted in the strategic human resource (HR) management frame has mostly focused on how organizations capitalize on their knowledge stocks (Lepak \& 
Snell, 1999; Kang, Morris \& Snell, 2007). Lepak and Snell (1999, 2002) proposed a framework, referred to as the human resource architecture, which emphasizes that the management of knowledge stocks embedded in employee groups within and across firm boundaries plays a central role in shaping value creation processes. This framework helps to integrate differences in knowledge and to create a picture of how a business' knowledge portfolio is managed. Further work by Kang et al. (2007) incorporates in the analysis specific strategies that businesses can adopt to optimize the management of knowledge workers. Human resource architecture models suggest how businesses allocate and manage different types of employees depending on both the characteristics of their knowledge - value (potential to improve performance) and uniqueness (degree of replicability) - and their relationship with the organization (core employees, internal employees, external partners and contract workers) (Kang et al., 2007).

Underlying HR architecture models is the assumption that business' competitive advantage primarily results from the effective exploitation of the core employees' knowledge base, while the knowledge of contract workers 'is neither of particularly high strategic value to a firm nor unique, thus becoming prime candidates for outsourcing' (Kang et al., 2007, p. 243). This implies that the value of knowledge is heterogeneous across employees, and that HR practices focused on the maximization of core employees' knowledge have the greatest impact on business performance.

Notwithstanding their significant contribution to the strategic HR management literature, HR architecture frameworks often underrate the value of contract workers on the basis that their knowledge and abilities are of little value and potential for the organization (Harney et al., 2014). As described by Kang et al. (2007), the main task of contract workers is to provide support to core or internal employees, which places them in a disadvantageous position relative to employees with permanent contracts. Although the validity of the approach by Kang et al. (2007), HR practices in knowledge-based organizations should also be aligned with specific characteristics of the work environment that may affect the contribution of contract workers to performance. In the specific context of universities this raises a number of issues of relevance to this study.

First, differences in the business' HR architecture mostly reflect differences in human capital among employees, in terms of the value and uniqueness of knowledge (Lepak and Snell, 2002, p. 519). In the case of universities, they employ contract workers on the basis that their knowledge is valuable and has the potential to enhance performance. Second, organizations increase the flexibility of their labor force by 
employing contract workers who perform tasks with limited scope (Lepak and Snell, 2002, p. 521). Nevertheless, contract workers play a key role in universities (Harney et al., 2014; Lissoni et al., 2011). The productivity of universities is a function of knowledge work in which the strong connection between scientists with permanent contracts and flexible contracts is critical to create knowledge outcomes and, consequently, enhance universities' research productivity.

If scientists with both permanent and temporary contracts have valuable and unique knowledge that can be used to increase research productivity, there are likely implications for the characteristics of the HR architecture. Within universities, the value-creating potential of young researchers' knowledge is comparable to that of scientists with permanent contracts (Harney et al., 2014). This unveils a discrepancy in the universities' HR practices that results from the mismatch between knowledge properties and the contract status afforded to fixed-term scientists. We argue that, along with knowledge properties (value and uniqueness), job security is a relevant dimension that should be accounted for in the HR practices of universities to achieve the desired goal of maximizing the knowledge generation process involving faculty with permanent and fixed-term contracts.

\subsection{Contract policy in universities and the research productivity of scientists}

The competitive advantage of universities heavily relies on scientists whose productivity stems from the exploitation of their knowledge and skills to solve novel, complex and abstract problems (Deem, Hylliard, \& Reed, 2007; Swart, 2007). Also, knowledge work takes place in an environment-i.e., within universities - where the high interdependence of tasks promotes the strong interaction between permanent scientists and other knowledge workers with flexible contracts (Harney et al., 2014).

Because academics - regardless of their contractual status - constitute a strategically valuable resource for universities, the development of HR management strategies is of paramount significance (Feng, Chen, Wang, \& Chiang, 2012; Lepak \& Snell, 1999). Echoing Kang et al. (2007), such practices in the higher education system should focus on the design of both flexible work structures and incentive systems that include pay, performance appraisal, and job security.

Therefore, it is important to question whether universities' HR contract practices align with scientists' interests or, on contrary, whether such HR policies increase job insecurity and send conflicting messages to scientists that affect their productivity. Prior 
studies indicate that factors related to independence and job security are highly valued by scientists (Agarwal \& Ohyama, 2014; Fuller \& Unwin, 2010; Harney et al., 2014).

Any attempt to answer this question requires the clarification of two different but complementary issues: the definition of research productivity and the identification of the HR contract practices employed by universities to manage knowledge workers.

Concerning the first issue, research productivity, existing research reveals that faculty promotion and tenure decisions are mostly based on faculty's publication records (Lissoni et al., 2011; Quimbo \& Sulabo, 2014). Thus, it is not surprising that scientists cater to the tastes of universities and seek to publish in scholarly journals as much as they can to meet the expectations. This approach to research productivity has resulted in HR practices - e.g., the use of journal lists in tenure, promotion and compensation systems — oriented to enhance universities' research productivity by encouraging scientists to target journals that on average receive more citations.

Nevertheless, the debate on what constitutes research productivity is open, and recent work underlines the need for adopting a holistic approach to scientists' productivity (Aguinis, Shapiro, Antonacopoulou \& Cummings, 2014; Bazeley, 2010). The main criticism to contemporaneous productivity metrics based on publication counts or citations is their narrow focus on a single stakeholder (i.e., academics), which implies that they do not provide information about impact on other stakeholders, such as policy makers or practitioners (Aguinis et al., 2014). Indeed, Pettigrew (2011, p. 348) suggests that 'including the impact of research in the social, economic and cultural spheres beyond academia is an important corrective to this displacement of goals'.

Recent technology advances have allowed the development of IT-based competencies - e.g., database management - that play a key role in the computation of more inclusive productivity measures (Aguinis et al., 2014). Yet, although scholars widely acknowledge the need to improve research productivity metrics, an agreement on what variables should be included and how to estimate productivity has not yet been reached. In the absence of a widely accepted definition of research productivity, policy makers - and, consequently, universities - in the US and Europe continue to evaluate scientists' productivity using publication metrics (Berbegal-Mirabent, Lafuente, \& Solé, 2013; Lissoni et al., 2011; Lutter \& Schröder, 2016; Quimbo \& Sulabo, 2014).

As for the second issue, HR policies, universities mostly employ two types of contracts to regulate their relationship with academics, namely, permanent contract and fixed-term contract (Lissoni et al., 2011). Traditionally, academics with permanent 
contracts are public servants who possess knowledge and experience that are core to the university. Also, experienced scientists may have developed networks and specific capabilities in managing research teams which, in turn, can contribute to increase university performance (Ryazanova \& McNamara, 2015). Concerning research productivity, existing work on human capital accumulation (Levin \& Stephan, 1991) stresses that scientists' productivity declines with age (e.g., Boardman \& Ponomariov 2007; Hall et al., 2007). In a scenario of age-driven productivity slow-downs, incentives to publish are likely determined by the scientists' interest in both consolidating research projects and increased reputation (Balsmeier \& Pellens, 2014). Thus, permanent scientists might compensate their potential productivity decline with activities linked to the training of junior researchers so that the university's productivity is not depressed. Also, aged scientists may be still prolific in supporting young researchers and identifying promising research avenues that they do not pursue personally.

Fixed-term contracts introduce flexibility in the universities' HR management practices. Contrary to academic inbreeding, this type of contract facilitates external recruitment, which increases mobility of academics and favors competition (Ackers \& Oliver, 2007; Paradeise, 2012). Scientists with a fixed-term contract are often young and promising researchers whose tasks are primarily oriented to produce research outcomes. Although its generally accepted advantages, a policy heavily based on the use of fixed-term contracts might generate unintended negative effects related to job precariousness and the poor exploitation of the university's knowledge base (Harney et al., 2014). More concretely, fixed-term contracts might create job insecurity which materializes in short-term job offers, high turnover rates, and high levels of stress among academics (Bryson \& Barnes, 2000; Metcalf, Rolfe, Stevens, \& Weale, 2005). Low internal promotion opportunities resulting from HR practices that saturate universities with fixed-term scientists increase the number of academics with shorter length of service that leave the university and search for a more stable position in the industry (Agarwal \& Ohyama, 2014; Balsmeier \& Pellens, 2014; Hall et al., 2007).

The core of our analysis is to scrutinize the effects on universities' research productivity of HR contract employment practices. Based on these arguments and evidence we hypothesize:

H1: The research productivity of scientists with fixed-term contracts is greater than that of faculty with a permanent position. 


\section{Research context: Regulatory framework and academic career in Spain}

In Spain, similar to other EU countries, the university system has gone through significant modifications during the past decades. Before 2001, the Organic Law of Universities (LRU) 11/1983 was the legal framework regulating the relationship between universities and faculty (permanent or fixed-term). In 2001 a profound reform took place, and with the enactment of the new Universities Act (LOU, 6/2001) higher education institutions enjoyed greater autonomy to restructure the faculty selection process. Also, the Spain's Government created in 2002 the Agency for Quality Assessment and Accreditation Trust (ANECA) to evaluate and endorse the scientific activity of university researchers. Similar agencies with the same attributions were created in various Spanish regions. With the new regulatory frame governing the university system in place, faculty witnessed a significant shift in how their research productivity affects the development of their academic career. In this new scenario, universities' research orientation is further emphasized, and the parameterization of research outputs facilitates the evaluation of universities and scientists (see Figure 1).

--- Insert Figure 1 about here ---

Yet, upon closer inspection it turns out that publication incentives are not equally distributed among faculty. In the case of permanent faculty, the 2001 Universities Act had no impact on their publication incentives, as this law did not introduce any modification into the evaluation process of their scientific outputs. Despite the new regulation, the number of vacancies for new permanent faculty was predetermined by public authorities, being seniority a key aspect in the evaluation process. Following the spirit of the LOU Act of 2001, a complementary reform took place in 2007 (Reform of the Organic Law of Universities (RLOU) 4/2007) on the accreditation process for candidates to permanent (civil servant) positions. This reform brought about two main changes in the Spain's system. First, the typology of permanent faculty was narrowed down to two (Senior Lecturer and Full Professor). Second, candidates to a permanent position have to undergo a more stringent evaluation process, where the positive assessment by ANECA — or the competent regional agency — is now critical. Although regulatory changes, publication incentives of permanent faculty remain low as their productivity is not evaluated once they obtained the position. 
The recruitment and assessment of fixed-term faculty also experienced significant variations. The 2001 Universities Act introduced the position of part-time faculty, which includes specialists with proven professional activity outside the university who perform a reduced number of teaching hours and, accordingly, they are paid hourly. The profile of this position - qualifications and tasks - makes it that the publication incentives for this group are low (or non-existent).

The RLOU Act of 2007 split the fixed-term position in three categories: assistant professor, $\mathrm{PhD}$ assistant lecturer, and $\mathrm{PhD}$ lecturers. For both assistant and $\mathrm{PhD}$ assistant professors the length of the contract is limited to four years. Lecturers enjoy a permanent contract; however, they do not have the status of civil-servant. Scientists can progressively move up through these three positions, provided that their merits are accredited by ANECA or the competent regional authority. More concretely, scientific publications weigh between $26 \%$ and $35 \%$ of the total evaluation. ${ }^{3}$ Thus, incentives to publish are high in these groups as a good publication record helps open the door either to an internal promotion within the university or to a position in another university.

The analysis of the characteristics of the Spanish university system provides some insights on how HR contract employment policies might affect research productivity. First, similar to other EU countries with centralized university systems, reforms in the Spanish university system give research productivity a key role on career advancement. Second, the reforms introduced in 2001 resulted in the parameterization of scientists' outcomes, which contributes both to interrupt career-by-seniority pathways common in Spain before 2001, and to create productivity incentives for young scientists.

The characteristics of the Spanish system suggest that fixed-term scientists should be more productive - due to publishing pressures for career progress - than permanent scientists whose publication record is not subject to scrutiny. These arguments-jointly with the deductions coming from the theory that underpins this study (section 2) -

\footnotetext{
${ }^{3}$ Qualitative information provided by colleagues from various EU countries (see footnote 1 for details) reveals that publications are the main indicator to evaluate scientists' productivity. However, the weight of research productivity in the evaluation equation is uneven across Europe. In the UK the quality of research outputs of schools and university departments is evaluated every six years within the Research Exercise Framework (REF). In the 2014 REF research outputs represented $65 \%$ of the final assessment of research quality of the analyzed unit (http://www.res.org.uk/details/mediabrief/5158051/EVALUATINGRESEARCH-QUALITY-How-peer-review-panels-should-make-their-REF-assessm.html). In other contexts the relevance of publication records is less parameterized, and the public administration empowers either university departments (Finland, Germany, and Italy) or accreditation agencies (Hungary) to decide on the weight of research productivity in the scientists' evaluation scorecard.
} 
justify the analysis of universities' research productivity, looking for a better understanding of how universities' HR policy contribute to capitalize on their scientists.

\section{Data, variable definition and method}

\subsection{Data}

In order to accurately analyze the connection between HR employment practices and the research productivity of Spanish public universities, we collected information from three different sources. First, the empirical analysis uses the bi-annual reports provided by the Spanish Association of University Rectors (Conferencia de Rectores de Universidades Españolas, CRUE) for the years 2002, 2004, 2006, and 2008. This organization brings together all Spanish universities and represents the main interlocutor between higher education institutions and the Spanish government. The CRUE databases contain organizational data as well as information about the configuration of the faculty of Spanish public universities, in terms of contractual status.

Second, the annual reports available from the Network of Spanish Technology Transfer Offices (RedOTRI) are used to obtain information about the publication record of Spanish public universities. Note that data on scientific publications included in these reports were gathered from the ISI Web of Science. Third, and with the objective of expanding the scope of the publication record of Spanish public universities, we manually collected - for each university - the total number of articles published in scholarly journals included in the SCOPUS databases. In this case, we collected the information on the scientific publications of Spanish public universities by matching the names of the universities with the identification name of the universities as assigned by SCOPUS. ${ }^{4}$ Note that the publications indexed in SCOPUS databases include scientific journals, books and conference proceedings. However, given the objective of the study, we limited the search to scientific articles published in scholarly journals in all scientific fields. Although we acknowledge that publications partially measure research productivity (Ryazanova \& McNamara, 2015), the available data allow at evaluating the research productivity of Spanish public universities using both quantity- and qualitybased publication metrics (Lissoni et al., 2011; Lutter \& Schröder, 2016).

\footnotetext{
${ }^{4}$ Because university names might appear in different ways (i.e., English and Spanish spelling) in the search tool available at the SCOPUS website, we double-checked the entries from the database in an effort to ensure that, for each university, all publications are correctly included in our dataset.
} 
In this study, the unit of analysis is the public university, and the final database comprises information for all Spanish public universities from 2002 to 2008 (47 universities and 188 observations).

It should be noted that that public universities are spread across all Spanish regions. More concretely, Andalucia (9 universities), Catalunya (7 universities) and Madrid (6 universities) are the regions with the greatest number of higher education institutions. On contrary, nine out of the 17 Spanish regions have one university. Additionally, 38 public universities have a medical school, while four out of the 47 institutions analyzed in this study are polytechnic universities.

\subsection{Variable definition}

Dependent variables. Similar to prior studies (e.g., Balsmeier \& Pellens, 2014; Berbegal-Mirabent et al., 2013; Lissoni et al., 2011), the knowledge output chosen to analyze universities' research productivity relates to the articles published in journals indexed in SCOPUS and the ISI-Web of Science. More concretely, we examine two dimensions of research productivity. First, a quantity-based measure defined as the total number of scientific articles published in academic journals-i.e., indexed in the SCOPUS database - divided by the total full time faculty (permanent and fixed-term contracts). Second, and similar to Lissoni et al. (2011) and Lutter and Schröder (2016), a quality-based variable measured as the number of scientific articles published in journals indexed in the ISI-Web of Science divided by total full time faculty.

At this point, we discuss three important aspects related to the computation of the dependent variables. First, the selection of publications per faculty as a measure of research productivity responds to the following criteria. On the one hand, scientists seek to maximize the value of their human capital by generating observable knowledge outputs, being publications a key indicator of academic success (Agarwal \& Ohyama, 2014; Balsmeier \& Pellens, 2014). On the other hand, as we indicated in section 3, the publication record is the most influential factor used by Spanish governmental agencies to evaluate the merit of scientists.

Second, publication outputs are conditioned by time and they do not necessarily follow the immediate exploitation of scientists' knowledge. For instance, researchers cannot control reviews and publication timing, thus creating a time span between the creation of the scientific article and its publication, i.e., scientists' research efforts are likely observable in following periods. Ignoring this time irregularity would yield 
biased results for research productivity. Following Lockett and Wright (2005) and Berbegal-Mirabent et al. (2013), we control for the time-varying relationship between knowledge exploitation by scientists and the observability of publication outputs. To achieve this, the computation of the research productivity of a focal university includes those papers published in period $t$ and in the subsequent period $(t+1)$.

Third, it should be kept in mind that underlying our definition of research productivity is the assumption that permanent and fixed-term professors generate publications. Part-time professors are specialists with market experience whose task strictly relates to teach a reduced number of hours. Thus, the proposed measure of publications by full-time faculty - i.e., excluding part-time contracts-accurately captures research productivity by incorporating in the estimation full-time scientists whose role in the university is linked to teaching and to the creation and dissemination of knowledge outputs.

Table 1 presents the descriptive statistics for the variables used in this study. Also, Figure 2 breaks research productivity into the two proposed measures and plots the average proportion of fixed-term contracts between 2002 and 2008. The figure shows not only the significant increase in research productivity between 2002 and 2008, but also the pronounced difference when compared to the pattern reported for the proportion of fixed-term contracts, a pattern that suggests that the employment of fixedterm contracts by Spanish public universities has grown faster than research productivity during the analyzed period.

--- Insert Table 1 about here ---

--- Insert Figure 2 about here ---

Contract status. Following the spirit of the Lisbon agenda, the enactment of the new regulatory framework in 2001 brought about important policy challenges. In the new scenario, Spanish public universities have strong incentives to employ scientists with publication potential, an objective that is strictly related to the policy makers' interest to increase the effectiveness of publicly funded science, and to measure the universities' research productivity on the basis of publication metrics. This study focuses on the relationship between the universities' contract employment policy and research productivity. The contract status of academics is measured via three variables which reflect the existing contract categories: the proportion of permanent faculty, 
measured by the ratio of permanent faculty relative to total faculty; the proportion of fixed-term contracts, calculated as the number of fixed-term faculty divided by total faculty; and the proportion of part-time faculty, measured as the ratio of part-time faculty divided by total faculty. In all model specifications the proportion of permanent faculty is the base category.

Control variables. We control for size, age, gender distribution, international networks, academic diversification and time in the different model specifications. University size is measured by the total number of faculty, while university age is expressed in years. Both size and age variables were logged to reduce skewness. Prior studies stress that gender is a non-meritocratic factor that might affect the road to success in academia and, consequently, university productivity (Jacob \& Lefgren, 2011; Lutter \& Schröder, 2016). To accurately assess the potential effects of the universities' gender configuration on research productivity we introduced in the analysis three variables capturing the proportion of men in each of the faculty categories analyzed in the study (permanent faculty, fixed-term professors, and part-time professors). International co-publications are often used as a measure of research collaboration, and they represent a partial indicator of (successful) collaborative networks (Jonkers \& Tijssen, 2008; Ryazanova \& McNamara, 2015). Thus, we use the proportion of international co-publications in scientific journals as a measure of co-authorship networks. Note that data on international co-publications available from the RedOTRI is restricted to papers visible on the ISI Web of Science database. We are aware that this variable partially captures the effect of international networks on research productivity. But, because publications in journals indexed in the ISI Web of Science represent $48.87 \%$ of the total publications during the analyzed period (see Table 1), we consider this variable a good proxy to measure collaborative networks.

Also, universities choose their set of academic degrees, and decisions on the degree of specialization result from several considerations where economic and market demand factors play a role. Following McMillan and Chan (2006) and BerbegalMirabent et al. (2013), we computed a Herfindahl index (HHI) for each university and in each period to control for the universities' academic diversification. The degrees offered by Spanish public universities are grouped into five categories: humanities studies, social sciences, natural sciences, medical sciences, and engineering studies. For ease of interpretation, we subtract the index from one, reversing the scale of this variable so that academic diversification increases as the index approaches one. Finally, 
we included a set of dummy variables to rule out the potential effect of time trends and other environmental changes (in all models 2008 was excluded as the base year).

\subsection{Methods}

In line with the arguments that underpin this study, we employ panel data techniques to estimate the proposed model which emphasizes a relationship between research productivity and the contract employment policies of universities. Pooling repeated observations on the same organizations violate the assumption of independence of observations, resulting in autocorrelation in the residuals. First-order autocorrelation occurs when the disturbances in one time period are correlated with those in the previous time period, resulting in incorrect variance estimates, rendering ordinary least squares (OLS) estimates inefficient and biased (Wooldridge, 2002). Therefore, we estimate fixed-effects panel data models with robust standard errors to take into account the unobserved and constant heterogeneity among the analyzed universities. Also, the use of fixed-effects models controls for the potential endogeneity problems that result from the correlation between the explanatory variables and the time-invariant university-specific unobserved heterogeneity (Greene, 2003).

To evaluate the role of universities' employment practices empirically, in the first stage analysis we propose a fixed-effects model with the following form: Research productivity $_{i t}=\beta_{0}+\beta_{1}$ Fixed-term contracts ${ }_{i t}+\beta_{2}$ Fixed-term contracts $^{2}{ }_{i t}$

$+\beta_{3}$ Part-time contracts $_{i t}+\beta_{4}$ Part-time contracts $_{i t}^{2}$ $+\beta_{5}$ Control variables ${ }_{i t}+T_{t}+\eta_{i}+\varepsilon_{i t}$

In equation (1) $\beta_{j}$ are parameter estimates for the $j$ th independent variable, $\eta$ is the time-invariant fixed effect that controls for unobserved heterogeneity across universities $(i)$, and $\varepsilon$ is the normally distributed error term that varies cross-universities and cross-time $(t)$. Control variables include university size, university age, the gender distribution of the analyzed universities, the proportion of international co-publications, and academic diversification, while $T$ refers to the set of time dummy variables.

We estimated the Hausman (1978) specification test to further validate the appropriateness of the proposed fixed-effects models. Results for model 1 (Hausman test: 26.49 and $p<1 \% ; 27.29$ and $p<1 \%$ ) and model 2 (Hausman test: 18.81 and $p<5 \%$; 38.11 and $p<1 \%$ ) indicate that random effects estimations are not independent of 
university-specific effects-i.e., regressors are inconsistent - thus confirming that fixedeffects estimations are consistent and efficient (Wooldridge, 2002).

Additionally, we propose a second stage analysis to provide further results on the relationship between universities' employment practices and research productivity. In this case, we are interested in testing whether growth patterns in research productivity are homogeneous across Spanish public universities and across time. We use coefficient estimates computed from equation (1) to analyze the trajectories of research productivity. Finally, the Wilcoxon signed-rank test was used for evaluating cross-time productivity comparisons.

\section{Results}

\subsection{Regression results}

The findings for the effect of employment practices in Spanish public universities on research productivity are presented in this section (Table 2). Model specification 1 in Table 2 shows the results for the baseline model estimating research productivity as a linear function of the proportion of fixed-term contract researchers and part-time faculty. Specification 2 reports the results for the full model that includes the linear and quadratic terms for the variables linked to the contract status of faculty.

To address the threat of collinearity, we computed the average variance inflation factor (VIF) for all variables. The average VIF value for model 2 is 7.48, and the only VIF values that exceed 10 - a generally accepted rule of thumb for assessing collinearity-were observed for the variables linked to the part-time faculty. By construction these terms are correlated and — even if computationally correct — this explains the VIF results (Greene, 2003). We computed VIFs for the variables used in model 1, and the resulting average VIF is 1.89 and ranges between 1.24 and 2.62. The results for this diagnostic test do not raise collinearity concerns.

The results of the control variables included in our analysis indicate that, throughout the different model specifications applied to our sample, smaller universities show higher rates of research productivity. Additionally, and in line with prior work (Jonkers \& Tijssen, 2008; Ryazanova \& McNamara, 2015), the findings reveal that research productivity is positively associated with the university's capacity to develop collaborative networks, in our case measured as the rate of international co-publications.

Concerning the fixed-effects model estimating the linear effect of employment practices on subsequent research productivity, results in model 1 of Table 2 show that- 
both for the ratio of total publications by faculty and the ISI publications by facultythe variables linked to the type of employment contract (fixed-term and part-time) are not statistically significant.

--- Insert Table 2 about here ---

Additionally, results in model 2 of Table 1 indicate that universities' HR practices linked to the contract relationships with scientists have a non-linear effect on publication outcomes. More concretely, the findings reveal an inverse-U shaped relationship between the proportion of fixed-term contracts and research productivity. This result gives partial support to the study hypothesis.

To help interpret the results, the quadratic term in model 2 presents only one breakpoint which can be derived by differentiating with respect to the proportion of fixed-term contracts, that is, $-\beta^{\% \text { Fixed-term contracts }} / 2 \beta^{\% \text { Fixed-term contracts }}{ }^{2}$. By solving the latter expression we know that, on average and compared to the proportion of permanent faculty, for universities whose proportion of fixed-term scientists is below $15.27 \%$ any increase in the proportion of this type of contracts will translate into a greater number of subsequent publications in indexed journals. In the case of the quality measure of research productivity - publications in journals indexed in the ISI Web of Science-our estimations suggest a positive relationship between the proportion of fixed-term contract researchers and subsequent research productivity in universities whose proportion of fixed-term contracts is below $17.02 \%$. On contrary, when the proportion of fixed-term academics with unprotected contracts is above the estimated breakpoints, the positive effects resulting from these researchers' publication incentives vanish. The estimated breakpoints are economically meaningful in that $57 \%$ of the analyzed universities (27 institutions) report a rate of fixed-term scientists above the cut-off point computed for the quantity productivity measure (15.27\%). When the proposed quality-based research productivity is the dependent variable, the results indicate that 19 universities have a proportion of fixed-term contracts above the estimated threshold value (17.02\%).

This result points to a paradox in which Spanish universities that adapt their employment policy to meet the productivity challenges set in place by reforms are not reaching the desired increases in research productivity. The results in Table 2 give 
support to the argument that flexible and balanced HR management practices are critical for enhancing universities' research productivity. Following the argument by Finegold and Frenkel (2006, p. 5), successful management of knowledge-workers result from the adoption of an approach that combines 'attachment to the firm based on intrinsic work satisfaction, selection for long-term potential and professional norms for oversight and control'. Nevertheless, results also indicate that research productivity in Spanish public universities is hampered by negative aspects that characterize fixed-term contracts including, for example, job insecurity and a lack of coherent career and professional development (Fuller \& Unwin, 2010).

\subsection{Second stage analysis}

At this point, we are interested in testing whether growth patterns in research productivity are homogeneous across the analyzed universities or, to the contrary, whether some universities effectively capitalize on their fixed-term researchers and achieve greater rates of research productivity over time. To achieve this objective, we carried out further analyses to explore the relationship between research productivity and universities' employment practices.

First, Figure 3 provides the estimated trajectories for the quantity- and qualityoriented research productivity measures, based on the coefficients of the linear and quadratic terms of the proportion of fixed-term contracts and at sample mean values of all other independent variables. The estimated trajectories of the two measures of research productivity are consistent with the view that-regardless of the university size, age, gender configuration, international collaborations and academic diversification - research productivity on average grows over time. Additionally, the estimated levels of research productivity are concave with respect to the universities' rate of fixed-term contract researchers.

\section{--- Insert Figure 3 about here ---}

Second, we evaluate the changes in research productivity and - for analytical purposes - we split the analyzed period in two sub-periods (2002-2004 and 2006-2008). We evaluate the research productivity of universities according to their level of fixedterm contracts and we distinguish between universities whose proportion of fixed-term contracts is below and above the cut-off points estimated from the regression analysis in 
Table 2 (quantity-based scientific productivity: 15.27\%, quality-based scientific productivity: $17.02 \%$ ). Table 3 shows the median level of research productivity and the Wilcoxon signed-rank test was used for the cross-time comparisons.

Results in Table 3 for the full sample (Panel A) indicate that research productivity grows over the analyzed period. Prior studies report that bibliometric measures of productivity increase over time (Balsmeier \& Pellens, 2014; Lissoni et al., 2011). The reported growth in research productivity is in line with the descriptive statistics (Figure 2) and the regression results (Table 2), thus confirming that this is the case in our data for both quantity and quality dimensions of research productivity.

In the case of the quantity-oriented measure (publications indexed in SCOPUS per full-time faculty), the median level of research productivity significantly increased from 0.8841 (2002-2004) to 1.0756 (2006-2008) and 42 out of the 47 analyzed public universities improved their results. Similar findings are reported for the quality-oriented measure of productivity-publications indexed in the ISI web of Science per full-time faculty — which improved from 0.4523 (2002-2004) to 0.5313 (2006-2008).

Notwithstanding the improvements in research productivity, it should be noted that HR employment practices of universities drastically changed and the median rate of fixedterm contracts increased more rapidly than research productivity (from $12.26 \%$ in the sub-period 2002-2004 to $22.88 \%$ in the sub-period 2006-2008).

--- Insert Table 3 about here ---

Results in Panel B of Table 3 show, for universities with a rate of fixed-term contracts below the cut-off points computed from regression estimates, the median level of fixed-term contracts and research productivity; while Panel $\mathrm{C}$ presents the median values of fixed-term contracts and research productivity for universities whose rate of fixed-term contracts is above the estimated cut-off points. The results in Panel B indicate that all universities with low levels of fixed-term contracts significantly improved their productivity results between the analyzed sub-periods (quantity-based productivity: $27.96 \%$ and quantity-based productivity: $29.84 \%$ ). When the quantitybased productivity measure is analyzed, the rate of fixed-term contracts increased up to a median value of $12.88 \%$ among universities with a rate of fixed-term contracts below the estimated cut-off point, while in the case of the quality-based productivity variable the median rate of fixed-term contracts significantly increased from $21.80 \%$ to $24.92 \%$. 
The comparison of the results in Panel $\mathrm{C}$ for both the quantity-based and the quality-based productivity reveals a drastic change in the evolution of research productivity. Among universities with an above-the-median level of quantity-based research productivity the rate of fixed-term contracts grew $14.30 \%$ during the analyzed period (from $21.80 \%$ to $24.92 \%$ ), while research productivity only improved $0.82 \%$. For the quality-based productivity measure, results show that the rate of fixed-term contracts remained practically unchanged among universities whose rate of fixed-term contracts is above the estimated cut-off point (from $25.92 \%$ to $25.68 \%$ ); however, their median level of research productivity decreased $8.38 \%$ (from 0.5714 to 0.5235 ).

\subsection{Robustness checks}

We conducted two additional analyses to further verify the robustness of our results. The first robustness test evaluates the validity of the proposed measure of research productivity. In our analysis we argue that scientists do not control publication timing and their research productivity does not follow the exploitation of their knowledge. To further control for the time-varying relationship between knowledge work and publication outcomes, we computed an alternative measure of research productivity that includes papers published in the two periods following each of the analyzed years (period $t+1$ and $t+2){ }^{5}$ Fixed-effects regression models were estimated based on equation (1) and results for this supplementary analysis, not presented due to space limitations but available on request, indicate that subsequent research productivity is not related to universities' HR employment policy in a significant way.

The second robustness test deals with the relationship between HR employment practices and research productivity. Having confirmed the non-linear (inverse Ushaped) effect of universities' HR contract policies on research productivity, one would be tempted to consider additional effects. Therefore, we computed the cubic term of the variables linked to the fixed-term and part-time contracts to test whether the relationship between HR employment practices and research productivity is S-shaped. The results, not presented but available from the authors on request, show that the linear coefficient for the variable 'fixed-term contracts' is positive and significant ( $p$-value $=0.052$ ), while the squared $(p$-value $=0.997)$ and cubic $(p$-value $=0.243)$ terms are not

\footnotetext{
${ }^{5}$ Note that papers published in period $t$ are not included in the computation of the research productivity variable to avoid 'double-counting' problems resulting from the overlapping of time periods.
} 
statistically significant. Once more, these results corroborate both the appropriateness of our estimation strategy to analyze research productivity and the validity of our findings.

\section{Discussion}

In the increasingly competitive arena of higher education, universities are adopting different strategies to enhance their research productivity levels (Sousa, de Nijs \& Hendricks, 2010). Although the debate on what constitutes research performance is open (see, e.g., Aguinis et al., 2014), universities are progressively using research productivity variables based on publication metrics to both signal the quality of their research and position themselves in the industry (Lissoni et al., 2011; Lutter \& Schröder, 2016). In a scenario where fixed-term scientists tend to cater to the tastes of universities, the analysis of how HR employment policies affect universities' research productivity gains relevance.

As in many European countries (Lissoni et al., 2011), Spanish universities use fixed-term contracts to attract young and promising researchers on the basis that some characteristics of this contract (flexibility and increased mobility) positively impact research productivity by offsetting the effects of academic inbreeding (Ackers \& Oliver, 2007; Horta et al., 2010). Yet, studies on HR management show that the short-termism and high turnover rates linked to this type of contract may increase job insecurity, which translates in lower research productivity (Harney et al., 2014; Metcalf et al., 2005).

It was found a non-linear relationship between the rate of fixed-term contracts and university research productivity. These results support that contract practices shape research productivity, and that the sign of this relationship is determined by the intensity with which universities use fixed-term contracts. In our interpretation, HR practices based on fixed-term contracts are conducive to productivity; but, some aspects of this contract foreshadow declining research productivity. This suggests that the relationship between universities and fixed-term scientists is governed by practices that not always match the characteristics of the knowledge of scientists (Kang et al., 2007).

Models on the HR practices of knowledge-intensive businesses mostly underline the role of core employees as reference group on the basis that their superior knowledge has the greatest impact on business performance (Lepak \& Snell, 2002). But, our results suggest that, given their value-creating potential, the reference groups upon which universities' HR practices should focus are scientists with both permanent and fixedterm contracts. Therefore, to be sure that research productivity reaches its full potential, 
flexible and balanced HR employment practices that harmonize knowledge properties and the scientists' contract status are needed (Kang et al., 2007).

Universities choose scientists to maximize scientific outcomes and knowledge exploitation plays a critical role in the equation of research productivity (Agarwal \& Ohyama, 2014). The results suggest that the excessive use of fixed-term contracts may deteriorate research productivity. Although universities promote knowledge-sharing practices - e.g., internal collaborations - to enhance their productivity levels (Boardman \& Corley, 2008; Ryazanova \& McNamara, 2015), our results for universities with high rates of fixed-term scientists are more in line with prior studies stressing that differences in the contract status may fracture the organizational climate which is critical for knowledge generation processes (Collins \& Smith, 2006; Harney et al., 2014).

Notwithstanding the value and research potential of the knowledge of fixed-term scientists, their uncertain professional development may well result not only from the short-term and unprotected conditions of their contracts (Harney et al., 2014), but also from obscure opportunities for advancement linked to a short-term contract employment policy which, in our view, materializes in high rates of fixed-term contracts. Our results pointing to a negative relationship between fixed-term contracts and research productivity in universities with high rates of fixed-term scientists are in line with this intuition. Low promotion opportunities exacerbated by HR practices that saturate universities with fixed-term scientists are detrimental to research productivity by increasing the number of fixed-term scientists who search for a more stable job in the industry (Agarwal \& Ohyama, 2014; Hall et al., 2007).

Research productivity is the observable outcome of scientists' efforts, and from our results we conclude that universities' HR contract practices should accommodate the scientists' interests if the knowledge generation process that precedes research productivity is to work.

\section{Concluding remarks, implications and directions for future research}

In this study, we proposed that contractual employment practices impact universities' research productivity. Furthermore, we argued that the publication incentives of fixed-term scientists, along with differences in investments in knowledge workers within academia have implications for the research productivity of universities. Our approach offers a compelling vision of how universities seek to enhance their research productivity through $\mathrm{HR}$ employment practices which, in turn, might generate 
unintended negative effects on both researchers' career development and universities' research productivity levels.

Overall, the findings are consistent with prior studies that emphasize that fixedterm contracts contribute to reduce the potentially negative effects of academic inbreeding on research productivity (Horta et al., 2010; Song et al., 2003). Nevertheless, we find that the excessive use of fixed-term contracts by universities is associated with declining research productivity (Fuller \& Unwin, 2010; Harney et al., 2014).

The findings of this study have relevant policy implications. Reforms in the Spain's higher education system aimed at creating the conditions for enhancing universities' productivity via the hiring of young and promising researchers with a fixed-term contract. Within academia, this notion is in line with the primary focus on research productivity which is fueled by reward structures that promote non-pecuniary motives such as priority of discovery, recognition of merits, and reputation (Agarwal \& Ohyama, 2014). In this scenario, this logic suggests that the brightest and top fixed-term researchers will move up to a permanent position within the university, provided that their research merits are accredited. Nevertheless, increased use of fixed-term contracts may create an uncertain work environment that undermines researchers' publication incentives, and this may translate into lower rates of scientific productivity, in terms of creation and dissemination of knowledge outputs.

In general, higher education institutions lag behind the adoption of effective strategies to retain their knowledge workers (Sousa et al., 2010). While fixed-term contracts might prove themselves a useful tool to enhance universities' publication outcomes and mobility is an important aspect for the development of researchers' careers, in the long-term the adoption of this contractual strategy can make universities to fall into a 'catch 22' loop characterized by unattractive career dynamics for young scientists, thus threatening universities' efforts to enhance their research productivity through HR contract strategies focused on the use of fixed-term contracts.

Our results suggest that the development of a HR contract policy based on fixedterm contracts is infiltrating into Spanish universities. Additionally, the analysis of the productivity trajectories of Spanish universities shows that this contractual strategy might limit the universities' capacity to capitalize on their knowledge workers. Therefore, the large budget lines invested by public administrations in universities and research centers should be coupled with appropriate workforce policies so that these 
investments do not turn into the sponsorship of institutions that offer unattractive academic careers.

It must, however, be mentioned a series of limitations to the present study that, in turn, represent avenues for future research. First, underlying our analysis of research productivity is the assumption that publications are the desirable output for scientists. Although research productivity is an important dimension of the scientific productivity construct, the channels used to disseminate research outputs vary across disciplines. Following Aguinis et al. (2014) and Ryazanova and McNamara (2015), future work should adopt a more pluralist approach to university productivity by taking into account the different outlets through which scientists communicate their findings.

Second, like other studies on research productivity (see, e.g., Lutter \& Schröder, 2016; Quimbo \& Sulabo, 2014), the data do not permit the direct analysis of the underlying knowledge generation process. We present various interpretations of how research productivity is conditioned by universities' contractual practices; however, we do not evaluate how productivity varies at different stages of the researchers' contract, nor do we assess the processes through which researchers generate-individually or collectively - publications. Further research on this issue would be valuable. For example, future studies should evaluate the researchers' response to new recruitments by universities, and determine whether academics at early stages of their contract publish more than researchers in the last contract year.

Third, and in line with our previous comment, differences in publication incentives between (and within) fixed-term and permanent scientists might result in productivity differentials between (and within) the two, which would contribute to further explain productivity gaps across universities. In contexts, such as universities, where income is mostly invariant with performance, Nickerson and Zenger (2008) comment that peer envy resulting from discontent employees and adverse work environmental conditions might trigger uncooperative behaviors. Future studies should corroborate if this argument holds for fixed-term scientists. From a HR management perspective, specifically designed future research can address this point by evaluating the potential effect of cooperation and peer envy on research productivity. Finally, cultural contexts, different regulatory frameworks, and variations in the flexibility and development of job markets might affect the impact of contract employment policies on research productivity. The geographic specificity of the study calls for obvious caution when interpreting and generalizing its findings. 


\section{References}

Ackers, L., Oliver, L. (2007). From Flexicurity to Flexsecquality?: The Impact of the Fixed-Term Contract Provisions on Employment in Science Research. International Studies of Management \& Organization, 37(1), 53-79.

Agarwal, R., Ohyama, A. (2014). Industry or academia, basic or applied? Career choices and earnings trajectories of scientists. Management Science, 59(4), 950-970.

Aguinis, H, Shapiro, D.L., Antonacopoulou, E., Cummings, T.G. (2014). Scholarly impact: A pluralist conceptualization. Academy of Management Learning \& Education, 13(4), 623-639.

Balsmeier, B., Pellens, M. (2014). Who makes, who breaks: Which scientists stay in academe? Economics Letters, 122(2), 229-232.

Bazeley, P. (2010). Conceptualizing research performance. Studies in Higher Education, 35(8), 889-903.

Berbegal-Mirabent, J., Lafuente, E., Solé, F. (2013). The pursuit of knowledge transfer activities: An efficiency analysis of Spanish universities. Journal of Business Research, 66(10), 2051-2059.

Boardman, P., Corley, E. (2008). University Research Centres and the Composition of Research Collaborations. Research Policy, 37(5), 900-913.

Boardman, P.C., Ponomariov, B.L. (2007). Reward systems and NSF university research centers: The impact of tenure on university scientists' valuation of applied and commercially relevant research. Journal of Higher Education, 78(1), 51-70.

Bonaccorsi, A., Daraio, C. (2003). Age effects in scientific productivity. Scientometrics, 58(1), 49-90.

Breschi, S., Lissoni, F., Montobbio, F. (2008). University patenting and scientific productivity: A quantitative study of Italian academic inventors. European Management Review, 5(2), 91-109.

Bryson, C., Barnes, N. (2000). Working in Higher Education in the United Kingdom. In M. Tight (Ed.), International Perspectives on Higher Education Research, Volume 1 (pp. 147-185). Emerald Group Publishing Limited.

Clark, B.R. (1993). The Research Foundations of Graduate Education: Germany, Britain, France, United States, Japan. University of California Press: Berkeley, CA. 
Collins, C., Smith, K.G. (2006). Knowledge Exchange and Combination: The Role of Human Resource Practices in the Performance of High-Technology Firms. Academy of Management Journal, 49(3), 544-560.

Currie, G., Tempest, S., Starkey, K. (2006). New Careers for Old? Organisational and Individual Responses to Changing Boundaries. International Journal of Human Resource Management, 17(4), 755-774.

Deem, R., Hillyard, S., Reed, M. (2007). Knowledge, higher education, and the new managerialism: The changing management of UK universities. Oxford: Oxford University Press.

Donnelly, R. (2009). The Knowledge Economy and the Restructuring of Employment. Work, Employment and Society, 23(2), 323-341.

Dunkin, R. (2003). Motivating Knowledge Workers. Higher Education Management and Policy, 15(3), 41-49.

Ehrenberg, R., Kasper, H., Rees, D. (1991). Faculty turnover at American colleges and universities: Analyses of AAUP data. Economics of Education Review, 10(2), 99110.

European Commission (2007). Towards a European strategy in support of innovation in services: Challenges and key issues for future actions. Commission Staff Working Document, SEC 1059. Brussels: Commission of the European Communities.

European Commission (2013). Scientific evidence for policy-making: Research insights from Socio-economic Sciences and Humanities. Luxembourg: Publications Office of the European Union.

European Commission (2015). Annual Report on the ERC activities and achievements in 2014. Luxembourg: Publications Office of the European Union.

Feng, H.I., Chen, C.S., Wang, C.H., Chiang, H.C. (2012). The role of intellectual capital and university technology transfer offices in university-based technology transfer. The Service Industries Journal, 32(6), 899-917.

Finegold, D., Frenkel, S. (2006). Managing People where People Really Matter: The Management of Human Resources in Biotech Companies. International Journal of Human Resource Management, 17(1), 1-24.

Fuller, A., Unwin, L. (2010). 'Knowledge Workers' as the New Apprentices: The Influence of Organisational Autonomy, Goals and Values on the Nurturing of Expertise. Vocations and Learning, 3(3), 203-222. 
Goldfarb, B. (2008). The effect of government contracting on academic research: Does the source of funding affect scientific output? Research Policy, 37(1), 41-58.

Greene, W. (2003). Econometric Analysis, fifth edition. Upper Saddle River, NJ: Prentice Hall.

Guest, D. (2004). Flexible Employment Contracts, the Psychological Contract and Employee Outcomes: An Analysis and Review of the Evidence. International Journal of Management Reviews, 5(1), 1-19.

Hall, B.H., Mairesse, J., Turner, L. (2007). Identifying age, cohort and period effects in scientific research productivity: discussion and illustration using simulated and actual data on French physicists. Economics of Innovation and New Technology, 16(1/2), 159-177.

Harney, B., Monks, K., Alexopoulos, A., Buckley, F., Hogan, T. (2014). University research scientists as knowledge workers: contract status and employment opportunities. International Journal of Human Resource Management, 25(16), 22192233.

Hausman, J. (1978). Specification Tests in Econometrics, Econometrica, 46(6), 12511271.

Horta, H., Veloso, F.M., Grediaga, R. (2010). Navel gazing: Academic inbreeding and scientific productivity. Management Science, 56(3), 414-429.

Jacob, B.A., Lefgren, L. (2011). The impact of research grant funding on scientific productivity. Journal of Public Economics, 95(9), 1168-1177.

Jonkers, K., Tijssen, R. (2008). Chinese researchers returning home: Impacts of international mobility on research collaboration and scientific productivity. Scientometrics, 77(2), 309-333.

Kang, S.C., Morris, S.S., Snell, S.A. (2007). Relational archetypes, organizational learning, and value creation: Extending the human resource architecture. Academy of Management Review, 32(1), 236-256.

King, D.A. (2004). The scientific impact of nations. Nature, 430, 311-316.

Lee, S., Bozeman, B. (2005). The impact of research collaboration on scientific productivity. Social Studies of Science, 35(5), 673.

Lepak, D.P., Liao, H., Chung, Y., Harden, E.E. (2006). A conceptual review of human resource management systems in strategic human resource management research. Research in Personnel and Human Resources Management, 25(1), 217-271. 
Lepak, D.P., Snell, S. (1999). The Human Resource Architecture: Toward a Theory of Human Capital Allocation and Development. Academy of Management Review, 24(1), 31-48.

Lepak, D.P., Snell, S. (2002). Examining the human resource architecture: The relationships among human capital, employment, and human resource configurations. Journal of Management, 28(4), 517-543.

Levin, S.G., Stephan, P.E. (1991). Research productivity over the life cycle: evidence for academic scientists. American Economic Review, 81(1), 114-132.

Lissoni, F., Mairesse, J., Montobbio, F., Pezzoni, M. (2011). Scientific productivity and academic promotion: a study on French and Italian physicists. Industrial and Corporate Change, 20(1), 253-294.

Lockett, A., Wright, M. (2005). Resources, capabilities, risk capital and the creation of university spin-out companies. Research Policy, 34(7), 1043-1057.

Lutter, M., Schröder, M. (2016). Who becomes a tenured professor, and why? Panel data evidence from German sociology, 1980-2013. Research Policy, 45(5), 9991013.

McMillan, M.L., Chan, W.C. (2006). University efficiency: A comparison and consolidation of results from stochastic and non-stochastic methods. Education Economics, 14(1), 1-30.

Metcalf, H., Rolfe, H., Stevens, P., Weale, M. (2005). Recruitment and retention of academic staff in higher education. National Institute of Economic and Social Research, Research Report RR658: UK.

Nickerson, J.A., Zenger, T.R. (2008). Envy, comparison costs, and the economic theory of the firm. Strategic Management Journal, 29(13), 1429-1449.

Paradeise, C. (2012). Tools and Implementation for a New Governance of Universities: understanding variability between and within countries. In A. Curaj, P. Scott, L. Vlasceanu, L. Wilson (Eds.), European Higher Education at the Crossroads (pp. 573-598). Netherlands: Springer.

Pettigrew, A.M. (2011). Scholarship with impact. British Journal of Management, $22(3), 347-354$.

Quimbo, M.A., Sulabo, E. (2014). Research productivity and its policy implications in higher education institutions. Studies in Higher Education, 39(10), 1955-1971. 
Ryazanova, O., McNamara P. (2015). Socialization and proactive behavior: Multilevel Exploration of Research Productivity Drivers in the US Business Schools. Academy of Management Learning \& Education, 15(3), 525-548.

Reich, E.S. (2013). The golden club. Nature, 502(7471), 291-293.

Santo, S.A. (2005). Knowledge management: An imperative for schools of education. TechTrends, 49(6), 42-49.

Song, J., Almeida, P., Wu, G. (2003). Learning-by-hiring: When is mobility more likely to facilitate interfirm knowledge transfer? Management Science, 49(4), 351-365.

Sousa, C., De Nijs, W., Hendriks, P. (2010). Secrets of the beehive: Performance management in university research organizations. Human Relations, 63(9), 14391460.

Swart, J. (2007). HRM and Knowledge Workers. In P. Boxall, P. Purcell, and P. Wright (Eds.), Handbook of Human Resource Management (pp. 450-468). Oxford: Oxford University Press.

Wooldridge, J. (2002). Econometric Analysis of Cross Section and Panel Data. Cambridge, MA: The MIT Press. 


\section{List of figures}

Figure 1. Changes in the regulatory framework of the Spanish University system

1) Orientation:

2) Incentives to disseminate research:

3) Contracts \& research incentives:
Teaching-oriented centres | Research-oriented centres | Low:

No parameterization of researchers' outputs

- Permanent: Protected

4 categories

Low research incentives

High:

Researchers' outputs are

| highly parameterized

- Permanent: Protected - Permanent: Protected

4 categories 2 categories

| Low research incentives | Low research incentives

| New accession procedure |

- Fixed-term: Unprotected - Fixed-term: Unprotected - Fixed-term: Unprotected

\begin{tabular}{l|l|l}
2 categories & 4 categories & 3 categories
\end{tabular}

No research incentives | High research incentives $\quad$ High research incentives

Timing of changes in regulation

Source: Authors' elaboration.

Figure 2. Proportion of fixed-term contracts and research productivity of Spanish universities (period 2002-2008)

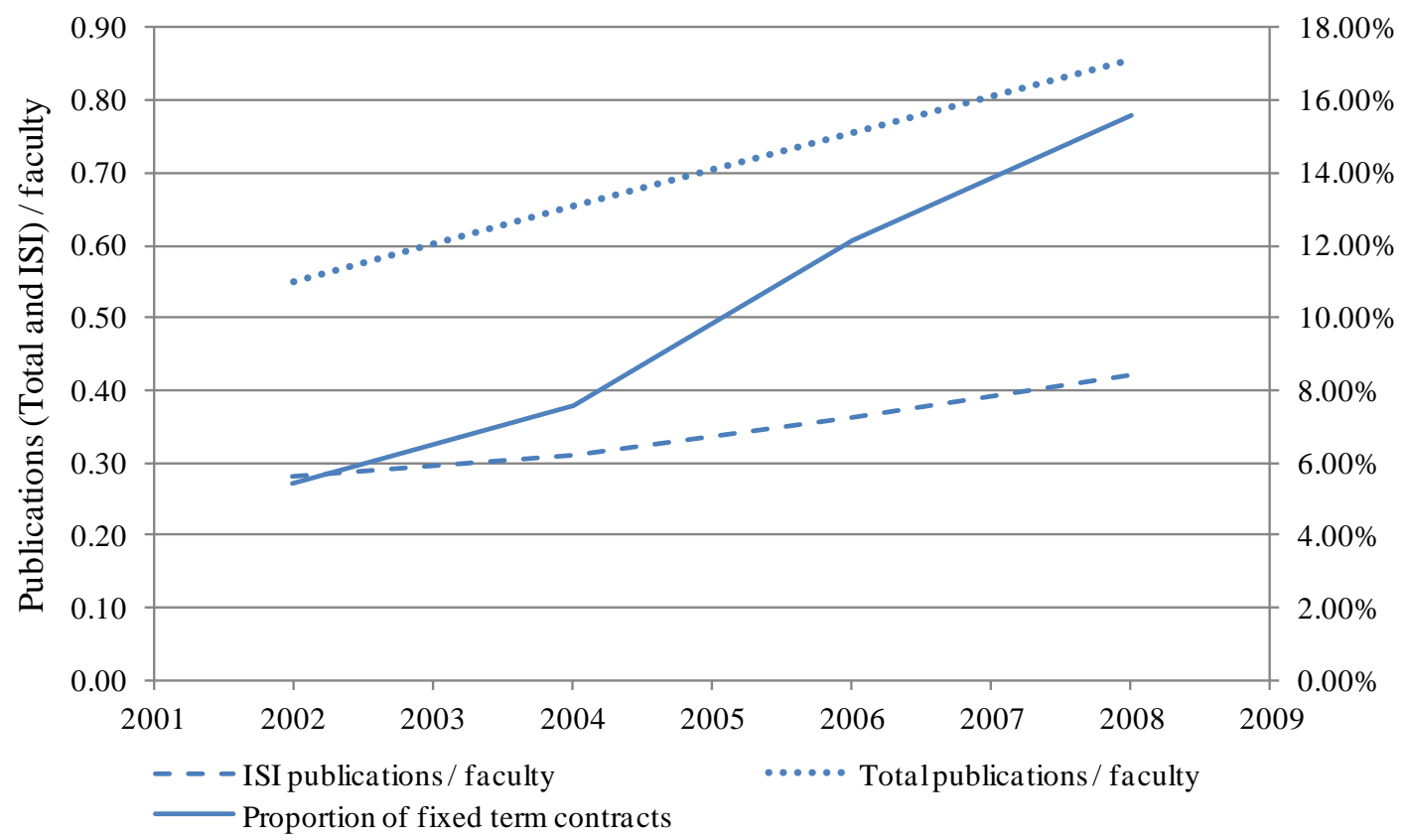

Source: Authors' elaboration. 
Figure 3. Estimated research productivity and fixed-term contracts (period 2002-2008)

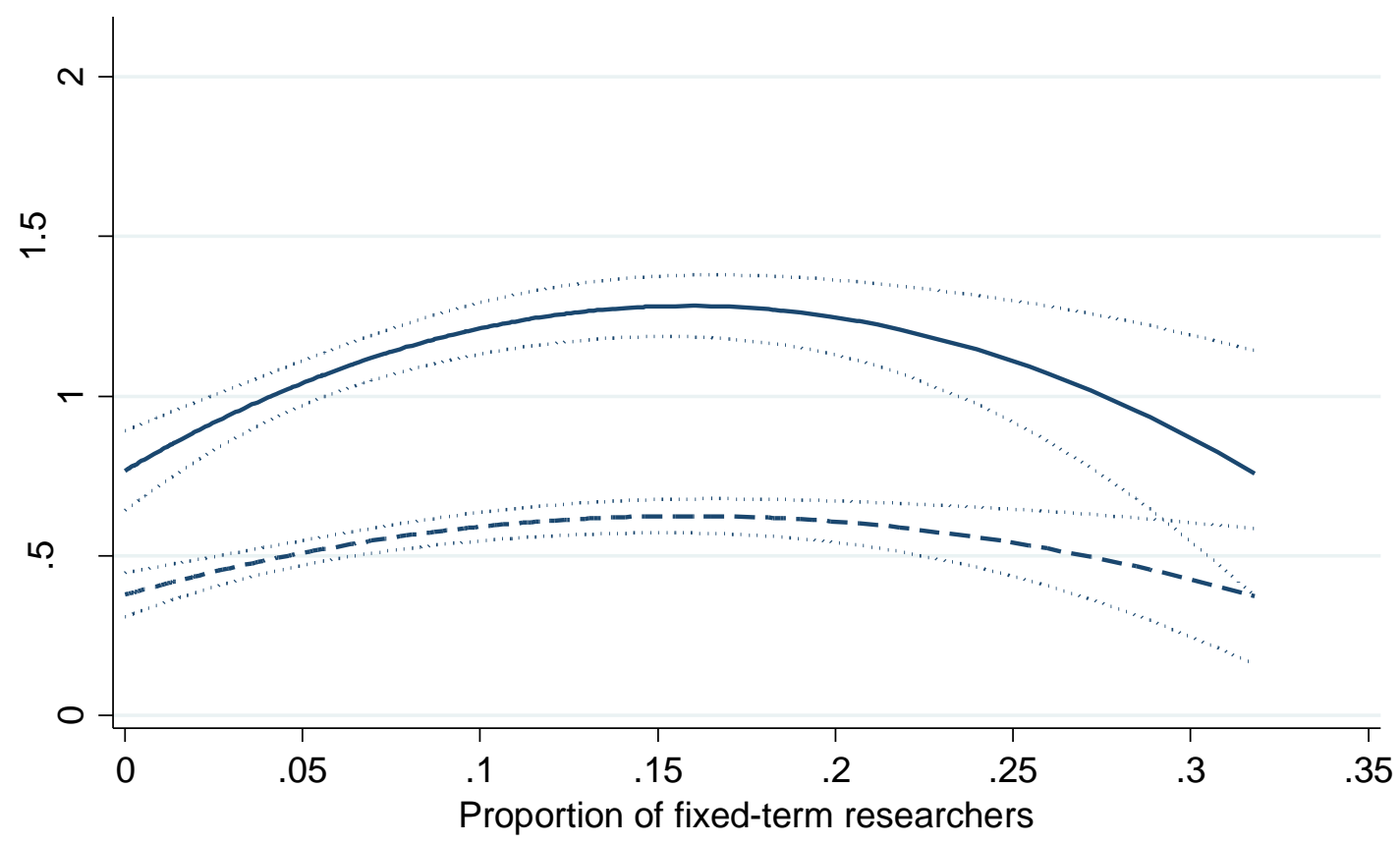

- Research productivity (total publications)

- - - Research productivity (for journals indexed in the ISI Web of Science)

Dotted lines represent 95\% confidence intervals. Source: Authors' elaboration. 


\section{List of Tables}

Table 1. Descriptive statistics for the selected variables

\begin{tabular}{|c|c|c|c|c|}
\hline & Mean & Std. Dev. & Minimum & Maximum \\
\hline Total number of publications / faculty & 1.0783 & 0.4569 & 0.2649 & 3.1305 \\
\hline ISI publications / faculty & 0.5271 & 0.2476 & 0.0503 & 1.6760 \\
\hline Proportion of permanent contracts & 0.5578 & 0.1080 & 0.2175 & 0.7815 \\
\hline Proportion of fixed-term contracts & 0.0867 & 0.0695 & 0.0000 & 0.3179 \\
\hline Proportion of part-time contracts & 0.3555 & 0.1062 & 0.1180 & 0.7487 \\
\hline Total faculty & 1924.70 & 1219.29 & 419.00 & 6249.00 \\
\hline University age (years) & 129.62 & 219.17 & 4.00 & 790.00 \\
\hline Educational scope (Herfindahl index $\left.{ }^{-1}\right)$ & 3.8419 & 0.8672 & 1.3680 & 4.8763 \\
\hline $\begin{array}{l}\text { Proportion of publications with } \\
\text { international collaboration }\end{array}$ & 0.3394 & 0.0684 & 0.2000 & 0.5361 \\
\hline Proportion of men: Permanent faculty & 0.6757 & 0.0560 & 0.5573 & 0.8624 \\
\hline Proportion of men: Fixed-term faculty & 0.4899 & 0.1613 & 0.0000 & 1.0000 \\
\hline Proportion of men: Part-time faculty & 0.6608 & 0.0954 & 0.0000 & 0.8966 \\
\hline
\end{tabular}

Sample size: 47 universities (188 observations during 2002-2008). 
Table 2. Fixed-effects results: The relationship between research productivity and universities' HR employment practices

\begin{tabular}{|c|c|c|c|c|}
\hline & \multicolumn{2}{|c|}{$\begin{array}{l}\text { Research productivity } \\
\text { (total publications / faculty) }\end{array}$} & \multicolumn{2}{|c|}{$\begin{array}{l}\text { Research productivity } \\
\text { (ISI publications / faculty) }\end{array}$} \\
\hline & (1) & (2) & (1) & (2) \\
\hline $\begin{array}{l}\text { Proportion of fixed-term } \\
\text { contracts }\end{array}$ & $\begin{array}{c}0.3219 \\
(0.4962)\end{array}$ & $\begin{array}{l}0.5294 * \\
(0.4022)\end{array}$ & $\begin{array}{c}0.0209 \\
(0.2196)\end{array}$ & $\begin{array}{l}0.6309 * * \\
(0.2460)\end{array}$ \\
\hline $\begin{array}{l}\text { Proportion of fixed-term } \\
\text { contracts (square term) }\end{array}$ & & $\begin{array}{c}-2.3876^{* *} \\
(1.0940)\end{array}$ & & $\begin{array}{c}-1.8534 * * * \\
(0.6046)\end{array}$ \\
\hline $\begin{array}{l}\text { Proportion of part time } \\
\text { contracts }\end{array}$ & $\begin{array}{l}2.3646 \\
(1.5710)\end{array}$ & $\begin{array}{c}1.1722 \\
(0.9350)\end{array}$ & $\begin{array}{c}1.2187 \\
(1.0779)\end{array}$ & $\begin{array}{c}0.8190 \\
(0.5362)\end{array}$ \\
\hline $\begin{array}{l}\text { Proportion of part time } \\
\text { contracts (square term) }\end{array}$ & & $\begin{array}{l}2.3405 \\
(2.0001)\end{array}$ & & $\begin{array}{l}1.0185 \\
(1.1462)\end{array}$ \\
\hline Size (ln total faculty) & $\begin{array}{l}-0.6828 * * \\
(0.2834)\end{array}$ & $\begin{array}{c}-0.9740 * * * \\
(0.3312)\end{array}$ & $\begin{array}{c}-0.4035 * * \\
(0.1943)\end{array}$ & $\begin{array}{c}-0.6714 * * * \\
(0.1789)\end{array}$ \\
\hline Age (ln university age) & $\begin{array}{c}0.2451 \\
(0.2158)\end{array}$ & $\begin{array}{c}0.2718 \\
(0.2227)\end{array}$ & $\begin{array}{c}0.0899 \\
(0.1034)\end{array}$ & $\begin{array}{c}0.1068 \\
(0.1066)\end{array}$ \\
\hline $\begin{array}{l}\text { Educational scope } \\
\text { (Herfindahl index } \\
\text { (-1) }\end{array}$ & $\begin{array}{c}0.0696 \\
(0.0689)\end{array}$ & $\begin{array}{c}0.0429 \\
(0.0658)\end{array}$ & $\begin{array}{c}0.0558 \\
(0.0419)\end{array}$ & $\begin{array}{c}0.0308 \\
(0.0348)\end{array}$ \\
\hline $\begin{array}{l}\text { Publications with } \\
\text { international collaboration }\end{array}$ & $\begin{array}{l}0.7093^{*} \\
(0.4497)\end{array}$ & $\begin{array}{l}0.7361^{*} \\
(0.4318)\end{array}$ & $\begin{array}{l}0.1164^{*} \\
(0.0651)\end{array}$ & $\begin{array}{l}0.1318^{*} \\
(0.0742)\end{array}$ \\
\hline $\begin{array}{l}\text { Proportion of men: } \\
\text { Permanent faculty }\end{array}$ & $\begin{array}{l}1.1362 \\
(1.5476)\end{array}$ & $\begin{array}{c}0.1553 \\
(1.1375)\end{array}$ & $\begin{array}{c}0.6385 \\
(0.9828)\end{array}$ & $\begin{array}{l}-0.1067 \\
(0.6808)\end{array}$ \\
\hline $\begin{array}{l}\text { Proportion of men: } \\
\text { Fixed-term faculty }\end{array}$ & $\begin{array}{c}0.0283 \\
(0.0871)\end{array}$ & $\begin{array}{c}0.0681 \\
(0.0898)\end{array}$ & $\begin{array}{c}0.0250 \\
(0.0381)\end{array}$ & $\begin{array}{c}0.0540 \\
(0.0392)\end{array}$ \\
\hline $\begin{array}{l}\text { Proportion of men: } \\
\text { Part-time faculty }\end{array}$ & $\begin{array}{l}-0.3817 \\
(0.2867)\end{array}$ & $\begin{array}{c}0.0197 \\
(0.2439)\end{array}$ & $\begin{array}{c}0.1889 \\
(0.1135)\end{array}$ & $\begin{array}{c}0.0615 \\
(0.1411)\end{array}$ \\
\hline Year 2002 & $\begin{array}{c}-0.5462 * * * \\
(0.0994)\end{array}$ & $\begin{array}{c}-0.5617 * * * \\
(0.1007)\end{array}$ & $\begin{array}{c}-0.3017 * * * \\
(0.0497)\end{array}$ & $\begin{array}{c}-0.3229 * * * \\
(0.0435)\end{array}$ \\
\hline Year 2004 & $\begin{array}{c}-0.3377 * * * \\
(0.0817)\end{array}$ & $\begin{array}{c}-0.3323 * * * \\
(0.0828)\end{array}$ & $\begin{array}{c}-0.2154 * * * \\
(0.0305)\end{array}$ & $\begin{array}{c}-0.2174 * * * \\
(0.0262)\end{array}$ \\
\hline Year 2006 & $\begin{array}{c}-0.1725^{* * * *} \\
(0.0316)\end{array}$ & $\begin{array}{c}-0.1629 * * * \\
(0.0318)\end{array}$ & $\begin{array}{c}-0.1164 * * * \\
(0.0166)\end{array}$ & $\begin{array}{c}-0.1140 * * * \\
(0.0149)\end{array}$ \\
\hline Intercept & $\begin{array}{l}3.5652 * * \\
(1.5176)\end{array}$ & $\begin{array}{l}6.2210 * * * \\
(1.8794)\end{array}$ & $\begin{array}{l}2.3320^{*} \\
(1.2411)\end{array}$ & $\begin{array}{l}4.6631 * * * \\
(1.1005)\end{array}$ \\
\hline $\mathrm{F}$ test & $16.41 * * *$ & $15.28 * * *$ & $13.05 * * *$ & $13.01 * * *$ \\
\hline R2 (within) & 0.6780 & 0.6925 & 0.6589 & 0.6959 \\
\hline Average VIF & 1.89 & 7.48 & 1.89 & 7.48 \\
\hline Hausman test & $26.49 * * *$ & $18.81 * *$ & $27.29 * * *$ & $38.11 * * *$ \\
\hline Observations & 188 & 188 & 188 & 188 \\
\hline
\end{tabular}

Robust standard error is presented in brackets. *, **, *** indicate significance at the $10 \%, 5 \%$ and $1 \%$, respectively. 
Table 3. Changes in research productivity

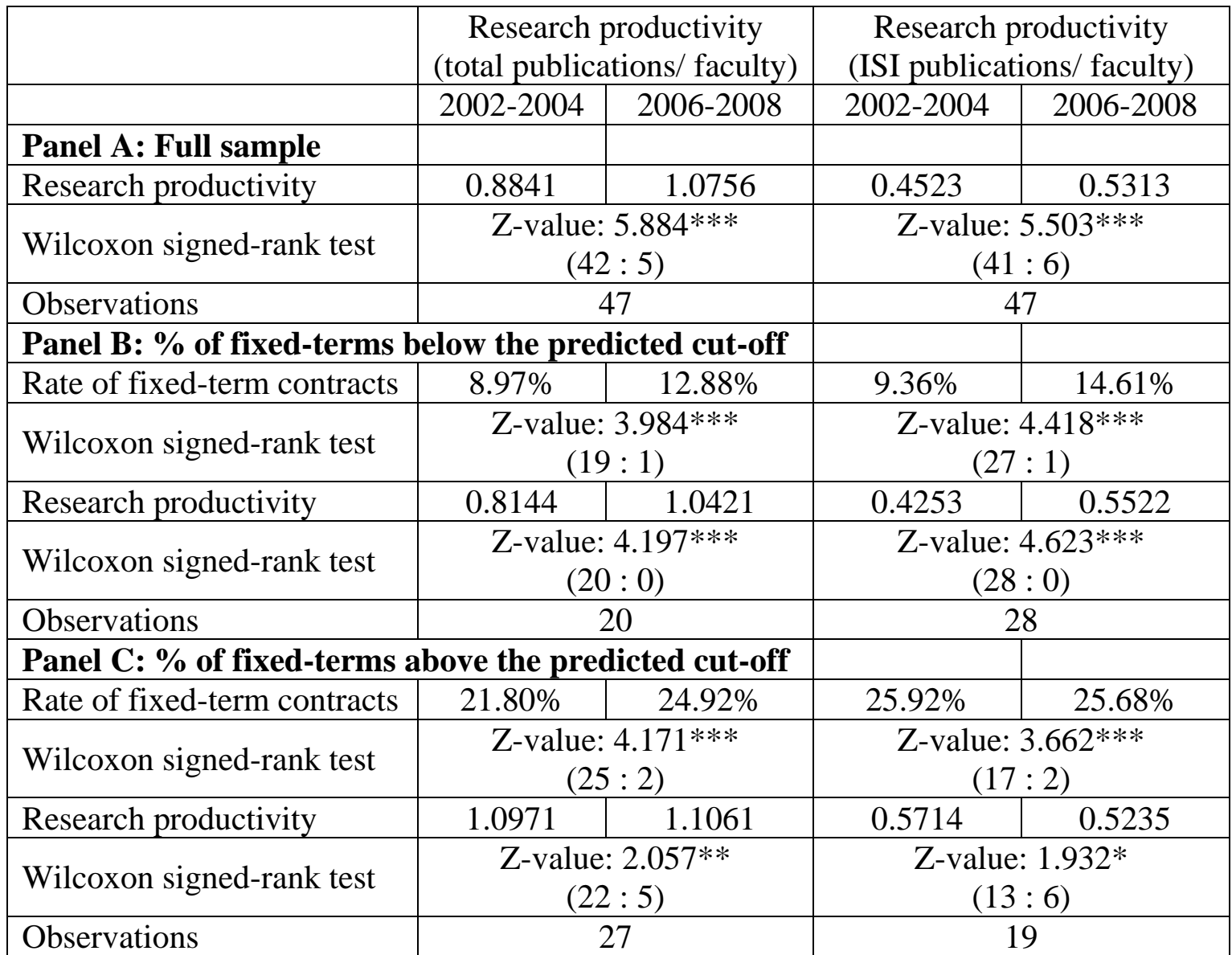

The table reports median values for the proportion of fixed-term contracts and research productivity. The predicted cut-off points are obtained from coefficients in Table 2 (total publications / faculty: $15.27 \%$ and publications in ISI journals / faculty: 17.02\%). Values in brackets refer to the number of universities with positive and negative changes in the focal variable between the two analyzed sub-periods (2002-2004 and 2006-2008). *,**,*** indicate significance at the $10 \%, 5 \%$ and $1 \%$, respectively. 